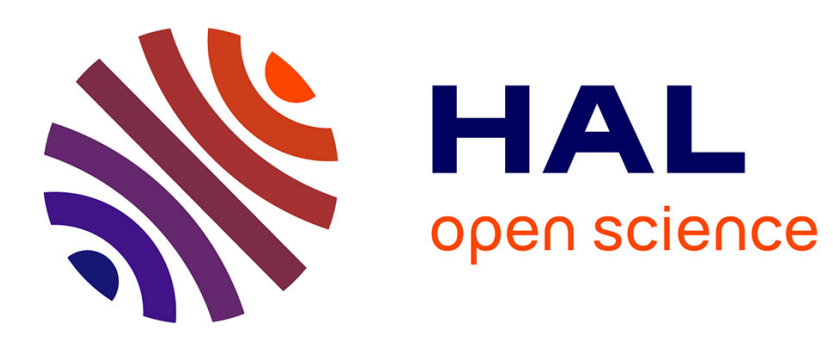

\title{
Continuous heatable Langmuir probe for flowing afterglow measurements
}

\author{
Sylvain Laubé, Toufik Mostefaoui, Bertrand Rowe
}

\section{To cite this version:}

Sylvain Laubé, Toufik Mostefaoui, Bertrand Rowe. Continuous heatable Langmuir probe for flowing afterglow measurements. Review of Scientific Instruments, 2000, 71 (2), pp.519-521. 10.1063/1.1150234 . hal-01290319

\section{HAL Id: hal-01290319 https://hal.science/hal-01290319}

Submitted on 9 Mar 2017

HAL is a multi-disciplinary open access archive for the deposit and dissemination of scientific research documents, whether they are published or not. The documents may come from teaching and research institutions in France or abroad, or from public or private research centers.
L'archive ouverte pluridisciplinaire HAL, est destinée au dépôt et à la diffusion de documents scientifiques de niveau recherche, publiés ou non, émanant des établissements d'enseignement et de recherche français ou étrangers, des laboratoires publics ou privés. 


\section{Continuous heatable Langmuir probe for flowing afterglow measurements}

Article in Review of Scientific Instruments - February 2000

DOI: $10.1063 / 1.1150234$

CITATIONS

5

3 authors:

\section{Sylvain Laubé}

European University of Brittany

37 PUBLICATIONS 310 CITATIONS

SEE PROFILE

Bertrand Rowe

Université de Rennes 1

136 PUBLICATIONS 3,163 CITATIONS

SEE PROFILE
READS

16

Some of the authors of this publication are also working on these related projects:

Project Project
1- Study and physical-chemistry characterization of North African archaeological/Art objects View project

1- Development of high sensitivity Raman spectrometer for the study of thin films and carbon nanomaterials View project

All content following this page was uploaded by Toufik Mostefaoui on 22 August 2015. 


\title{
Continuous heatable Langmuir probe for flowing afterglow measurements
}

\author{
Sylvain Laubé, ${ }^{\text {a) }}$ Toufik Mostefaoui, and Bertrand Rowe \\ Laboratoire "Physique des Atomes, Lasers, Molécules et Surfaces," U.M.R. du C.N.R.S. no. 6627 \\ Université de Rennes I, 35042 Rennes, France
}

(Received 16 June 1999; accepted for publication 28 September 1999)

\begin{abstract}
A heatable Langmuir probe consisting of a continuous dc-heating-current loop of tungsten wire is presented. This technique is efficient to keep the probe surface clean for flowing afterglow measurements. In our experimental conditions, the perturbations on the electron density determination can be considered as very small. The measurement of the well-known rate for the dissociative recombination of $\mathrm{O}_{2}^{+}$shows that the gas surrounding the probe is not heated for estimated probe temperature up to $700 \mathrm{~K}$. (C) 2000 American Institute of Physics.
\end{abstract}

[S0034-6748(00)01501-X]

\section{INTRODUCTION}

The Langmuir probe can be considered as a classical diagnostic tool for use in the determination of plasma parameters. The standard technique is to insert a small electrode into the plasma and to polarize it, electrically. The analysis of the current-voltage characteristic allows one to determine electron density, electron temperature and in certain circumstances, the electron energy distribution.

The flowing afterglow Langmuir probe-mass spectrometer (FALP-MS) apparatus in our laboratory employs this method in order to measure room temperature rate coefficients of ion-molecule reactions, electron attachment, and dissociative recombination for ions and molecules of astronomical interest. ${ }^{1-3}$ Contamination of the probe surface can lead to an erroneous determination of the plasma parameters due to a distortion of the probe characteristic. ${ }^{4}$ By polarizing the probe negatively or positively to a large potential, ion or electron bombardment can remove the contamination layer., ${ }^{5,6}$ This method is efficient however, only if the time scale for recontamination is large compared with the time needed to acquire the probe characteristic. In the case of plasma containing hydrocarbon ions, which we have used for dissociative recombination measurements, we observed that this condition is not always respected. To eliminate such contamination in $Q$ machines, a continuous indirect heating of the Langmuir probe is found to be efficient. ${ }^{7,8}$ To keep the probe surface clean during the FALP-MS measurements, a continuous direct heating of the Langmuir probe has been provided by using a dc-heating-current loop of tungsten wire.

We present here the design and operating characteristics of this continuously heated probe. The perturbations due to this system are discussed and the measurement of the wellknown rate for the dissociative recombination of $\mathrm{O}_{2}^{+}$shows that the electron density determination is not perturbed and that the gas surrounding the probe is not heated.

${ }^{a)}$ Electronic mail: laube@univ-rennes1.fr

\section{LANGMUIR PROBE DESIGN AND THE OPERATING SYSTEM}

Figure 1 shows the probe design we used for our investigations and Fig. 2 summarizes the heating and data aquisition system. The following method gives some ideas about temperature of the $W$ wire versus the heating current $\left(I_{h}\right)$. From the slope of the $V_{h}-I_{h}$ characteristic (where $V_{h}$ is the heating voltage applied to the wire), we obtain the ratio $R / R_{0}=g\left(I_{h}\right)$ (where $R$ is the resistance value of the wire when $I_{h}$ passes through it and $R_{0}$ is the value for $I_{h}=0 \mathrm{~A}$, i.e., at room temperature). We made the hypothesis that temperature is the same all along the $\mathrm{W}$ wire, and, in this case, the estimated temperature $T_{w}$ consists of the lower limit of the probe temperature. The resistivity $\rho$ of tungsten versus temperature is well known and, considering the dilatation phenomenon be small (i.e., $\rho / \rho_{0}=R / R_{0}$ ), it is easy to obtain the curve $T_{w}=h\left(I_{h}\right)$ (see Fig. 3).

\section{DISCUSSION ABOUT PERTURBATIONS DUE TO THE CONTINUOUSLY HEATED PROBE}

Due to the heating current, we have to take into account a voltage existing between the extremities of the probe (length $l$ ): if we call $V_{s 0}$ the probe voltage at $x=0$ (located in the middle of the probe), we have to consider that the voltage at $x= \pm l / 2$ is $V_{s 0} \pm \Delta V$. Two consequences have been considered:

(a) When no heating current exists (i.e., $\pm \Delta V=0 V$ ) and when the electron density is to be measured, the characteristic curve $V_{s}-I_{s}$ is usually analyzed in the region (so-called accelerating region under orbital-motionlimited current conditions) where $V_{s}>V_{p}+10 \mathrm{kTe} / q$, with $V_{p}$ being the plasma potential, $q$ the electron charge, $T_{e}$ electron temperature, and $k$ the Boltzmann constant. In the case of the continuously heated probe, analysis of the characteristic curve must be made on the region where

$V_{s}-\Delta V>V_{p}+I 0 k T_{e} / q$.

Under typical experimental conditions (probe radius $r_{s}=1.25 \times 10^{-3} \mathrm{~cm}, \quad T=700 \mathrm{~K}, \rho(T=700 \mathrm{~K})=16.09$ 
(4)

(5)

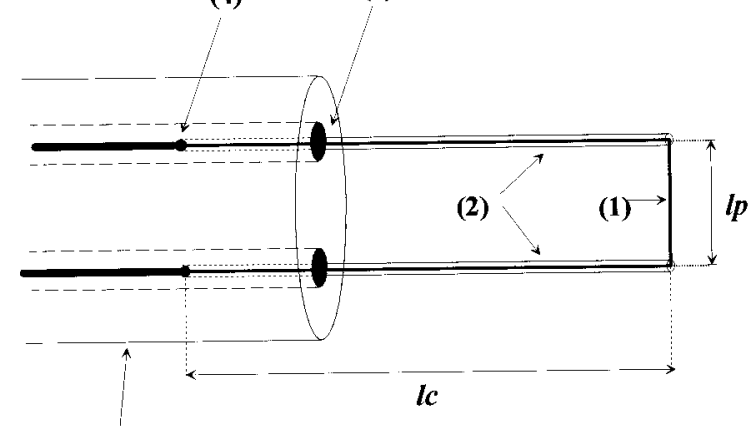

(3)

FIG. 1. Schematic of the Langmuir probe design: (1) tungsten wire of 25 $\mu \mathrm{m}$ diameter, $l_{p}=4 \mathrm{~mm}$, (2) glass capillary of $50 \mu \mathrm{m}$ internal diameter, $l c=13 \mathrm{~mm}$, (3) ceramic capillary containing two bores of $0.5 \mathrm{~mm}$ internal diameter, (4) soldered joints, (5) adhesive joints.

$\left.\mu \Omega \mathrm{cm}, I_{h}=130 \mathrm{~mA}, l=0.4 \mathrm{~cm}, T e=300 \mathrm{~K}\right), \Delta V$ is estimated to be $\cong 0.09 \mathrm{~V}$ (or $\cong 3.5 k T_{e} / q$ ).

(b) When the $W$ wire is heating (i.e., $\Delta V \neq 0 V$ ), errors in the electron density determination have to be estimated. If we consider that the Langmuir probe can be represented by the sum of elementary cylindrical probes of length $\delta l$ (such as $\Sigma \delta l=l$ ) centered at the position $x$, the elementary electronic current $\delta i$ collected at $\pm x$ is

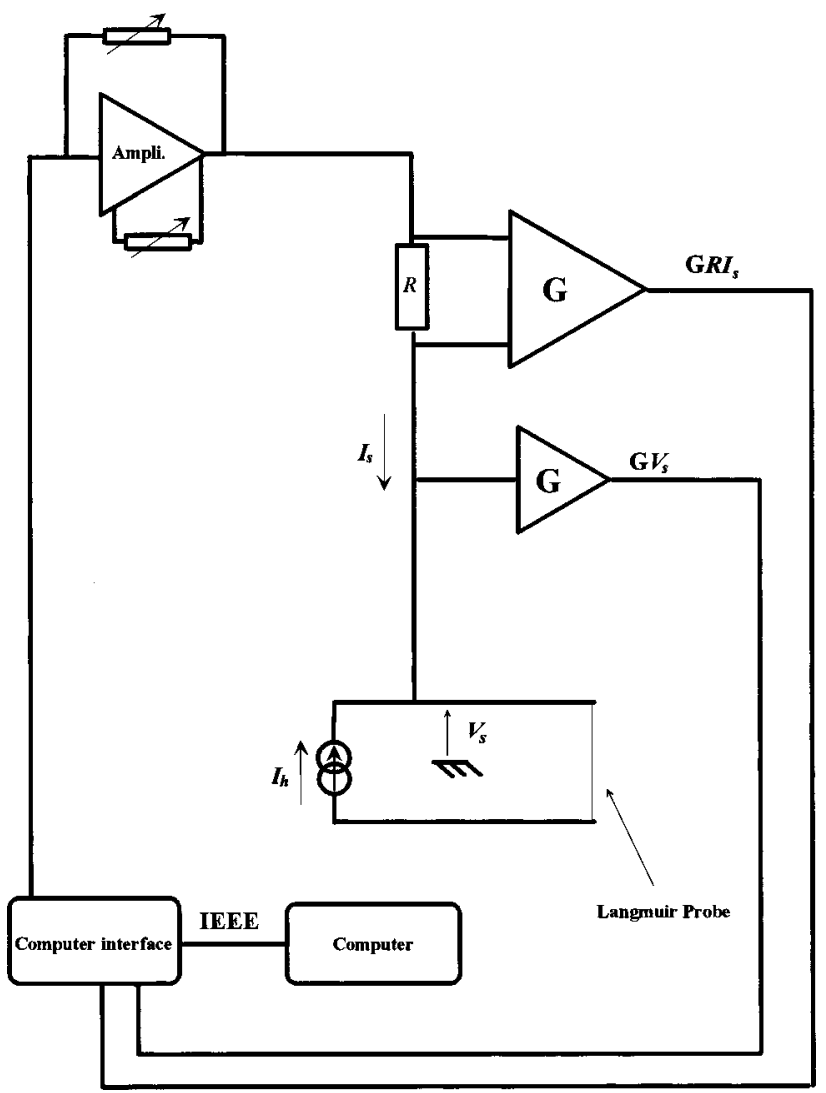

FIG. 2. Schematic of the heating and data aquisition system. The Langmuir probe (consisting of the $W$-wire loop) is heating by the dc current $I_{h}$. The electron density is calculated from the characteristic curve $V_{s}-I_{s}$.

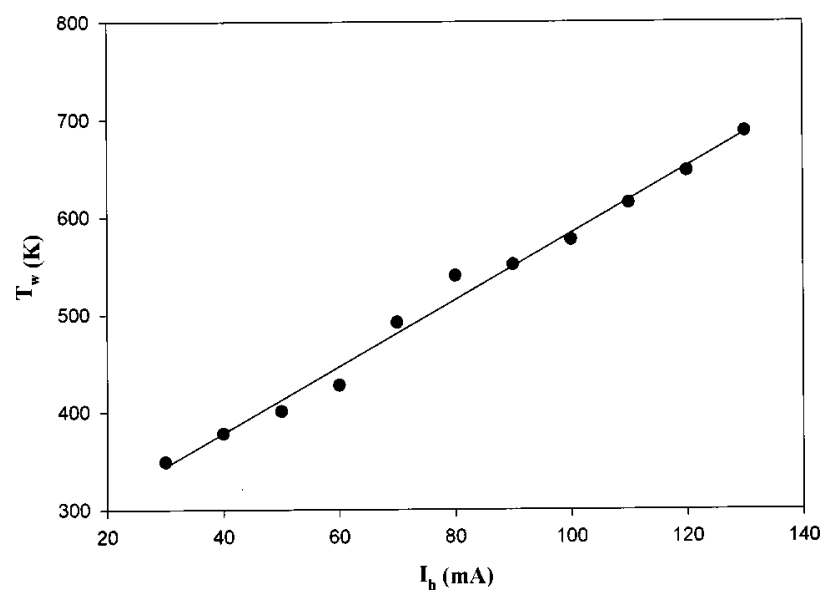

FIG. 3. Estimated temperature $T_{w}$ of the probe vs heating current $I_{h} . T_{w}$ is obtained from the measurements of the heated $W$-wire resistivity and consists of the lower limit of the probe temperature.

$$
\delta i( \pm x)=K\left(T_{e}\right) n_{e} \delta l \sqrt{1+\frac{q\left(V_{s 0} \pm \Delta V(x)\right)}{k T_{e}}},
$$

where $n_{e}$ is the electron density, $K\left(T_{e}\right)$ is a function of the electron temperature.

(c) By developing Eq. (2) and summing the terms at $+x$ and $-x$, we obtain,

$$
\begin{aligned}
\delta i(x)+\delta i(-x)= & K\left(T_{e}\right) n_{e} 2 \delta l \sqrt{\frac{q V_{s 0}}{k T_{e}}}\left(1+\frac{1}{2} \frac{k T_{e}}{q V_{s 0}}\right. \\
& -\frac{1}{8}\left[\left(\frac{\Delta V(x)}{V_{s 0}}\right)^{2}+\left(\frac{k T_{e}}{q V_{s 0}}\right)^{2}\right] \\
& \left.+o\left[\left(\frac{\Delta V(x)}{V_{s 0}}\right)^{3}\right]\right) .
\end{aligned}
$$

Accurate values of the electron density are obtained from the slope of the linear plots of $I_{s}^{2}$ versus $V_{s}$. Under our experimental conditions, linearity is still verified in the range from $V_{p}+50$ to $V_{p}+100 k T_{e} / q$. In this case, Eq. (1) is always respected. In the more unfavorable case (i.e., $\Delta V$ $=3.5 k T_{e} / q$ and $V_{s}=50 k T_{e} / q$ ), the perturbation can be estimated and considered as insignificant,

$$
\left[\left(\frac{\Delta V(x)}{V_{0}}\right)^{2}+\left(\frac{k T_{e}}{q V_{0}}\right)^{2}\right] \cong 0.5 \% \text {. }
$$

\section{IS THE PLASMA HEATED? DISSOCIATIVE RECOMBINATION OF $\mathrm{O}_{2}^{+}$AS A TEST}

If the medium surrounding the probe is heated, the plasma parameters can be perturbed. Measurement of the $\mathrm{O}_{2}^{+}$

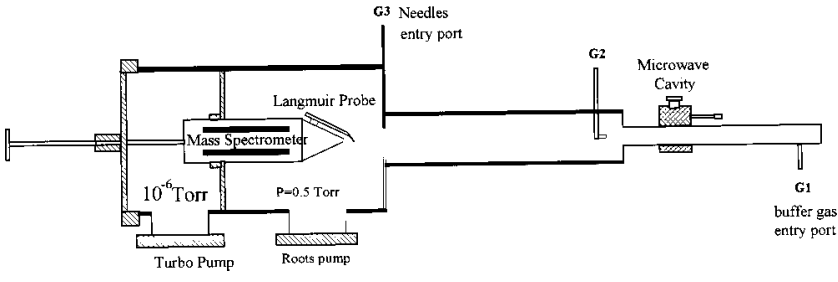

FIG. 4. Schematic of the FALP-MS apparatus 
TABLE I. Influence of the heated $\mathrm{W}$ wire on the gas surrounding the probe. The comparison between the measured $\alpha\left(\mathrm{O}_{2}^{+}\right)$(for different temperatures $T_{w}$ of the heated $\mathrm{W}$ wire) and the calculated $\alpha\left(\mathrm{O}_{2}^{+}\right)$(considering that the gas surrounding the probe is heated to the same temperatures) shows that no perturbation occurs up to $700 \mathrm{~K}$.

\begin{tabular}{lcccc}
\hline \hline \multicolumn{1}{c}{$T_{w}(K)$} & 300 & 480 & 590 & 690 \\
\hline $\begin{array}{l}\text { Measured } \alpha\left(\mathrm{O}_{2}^{+}\right) \\
\left(\mathrm{cm}^{3} \mathrm{~s}^{-1}\right)^{\mathrm{a}}\end{array}$ & $2.03 \times 10^{-7}$ & $2.12 \times 10^{-7}$ & $2.03 \times 10^{-7}$ & $1.9 \times 10^{-7}$ \\
$\begin{array}{l}\text { Calculated } \alpha\left(\mathrm{O}_{2}^{+}\right) \\
\left(\mathrm{cm}^{3} \mathrm{~s}^{-1}\right)^{\mathrm{b}}\end{array}$ & $1.95 \times 10^{-7}$ & $1.40 \times 10^{-7}$ & $1.21 \times 10^{-7}$ & $1.09 \times 10^{-7}$ \\
\hline
\end{tabular}

${ }^{a}$ Measured $\alpha\left(\mathrm{O}_{2}^{+}\right)$in this work vs the estimated temperature $T_{w}$ of the heated wire.

${ }^{\mathrm{b}}$ Calculated $\alpha\left(\mathrm{O}_{2}^{+}\right)$from the formula $\alpha\left(\mathrm{O}_{2}^{+}\right)=1.95 \times 10^{-7}\left(300 / T_{w}\right)^{0.7}$ (see Ref. 9).

dissociative recombination rate coefficient $\alpha\left(\mathrm{O}_{2}^{+}\right)$is a good test to show if in fact the plasma is perturbed since it has been well established that $\alpha=1.95 \times 10-7 \mathrm{~cm}^{3} \mathrm{~s}^{-1}$ at $300 \mathrm{~K}$ and is found to vary as $T^{-0.7}$. ${ }^{9}$

The FALP-MS experimental apparatus has been described in detail before ${ }^{10}$ and only a brief description is given here (Fig. 4). The technique is an extension of the conventional FALP technique ${ }^{11}$ that is supplemented by a movable mass spectrometer which is used to identify ions present in the measurement region of the afterglow and to measure the number density of these ions as a function of distance along the flow and of electron concentration. The measurement method is classical and very similar to the one described by Smith $^{9}$ and only the major facts are given here.

A helium buffer gas flow was ionized by a microwave cavity operating at $2.45 \mathrm{GHz}$. A pressure of 0.58 Torr was maintained in the flow tube during all measurements. The afterglow consisted of neutral ground state and metastable excited state helium atoms $\mathrm{He}^{*}, \mathrm{He}_{2}^{+}$and $\mathrm{He}^{+}$ions and electrons. The typical electron density is $5 \times 10^{10} \mathrm{~cm}^{-3}$. Argon gas was introduced at the second entry port $G 2$, downstream in order to produce, in the measurement area, an $\mathrm{Ar}^{+}$dominated plasma via the reactions

$$
\begin{aligned}
& \mathrm{He}^{+}+2 \mathrm{He} \rightarrow \mathrm{He}_{2}^{+}+\mathrm{He}, \\
& \mathrm{He}_{2}^{+}+\mathrm{Ar} \rightarrow \mathrm{He}+\mathrm{He}+\mathrm{Ar}^{+}, \\
& \mathrm{He}^{*}+\mathrm{Ar} \rightarrow \mathrm{He}+\mathrm{Ar}^{+}+e .
\end{aligned}
$$

The absence of $\mathrm{He}_{2}^{+}$in the mass spectrum (in the measurement area, about $80 \mathrm{~cm}$ after the argon injection through $G 2$ ) verified that reaction (6) had gone to completion, prior to arriving at the measurement region and from this, knowing the rate for reaction (7), one could be sure that all helium metastables had also been converted. In this case, due to the helium buffer, the hot electrons in the plasma were cooled within a few $\mu$ s by collisions and the condition where $T_{\text {gas }}$ $=T_{\text {ion }}=T_{e}=300 \mathrm{~K}$ was obtained.

Reactant gas $\mathrm{O}_{2}$ was introduced into the flow via an eight-needle entry port $(G 3) . \mathrm{O}_{2}^{+}$was produced via the charge exchange reactions

$$
\begin{aligned}
& \mathrm{He}+\mathrm{O}_{2} \rightarrow \mathrm{He}+\mathrm{O}^{+}+\mathrm{O}, \\
& \mathrm{O}^{+}+\mathrm{O}_{2} \rightarrow \mathrm{O}_{2}^{+}+\mathrm{O}, \\
& \mathrm{Ar}^{+}+\mathrm{O}_{2} \rightarrow \mathrm{O}_{2}^{+}+\mathrm{Ar} .
\end{aligned}
$$

At room temperature, clustering reactions generating $\mathrm{O}_{2}$. $\mathrm{O}_{2}^{+}$ can be considered to be small. Changes in the ion composition in the reaction area were monitored all along the axis by the movable mass spectrometer and allowed us to ensure that the reactions (8), (9), (10) were completed and that only $\mathrm{O}_{2}^{+}$ ions were present.

Neglecting diffusion loss, one can write down the equation giving the change in the electron density $n_{e}$ as a function of distance, $z$, along the flow tube, thus

$$
\frac{1}{n_{e}(z)}=-\frac{\alpha}{\nu_{p}} z+\frac{1}{n_{e}(z=0)} \text {. }
$$

The plot of $1 / n_{e}(z)$ against $z$ allows us to determine $\alpha$ (knowing the value of the flow velocity $\nu_{p}$ ).

Table I shows the measured $\alpha\left(\mathrm{O}_{2}^{+}\right)$versus the estimated temperature $T_{w}$ (up to $690 \mathrm{~K}$ ) of the heated $W$ wire (estimated with the method described above). All values are very similar and in agreement with a rate coefficient at $T$ $=300 \mathrm{~K}$, and we can consider that in this range of temperature no perturbation due to the heated probe occurs.

${ }^{1}$ A. Canosa, S. Laubé, C. Rebrion, D. Pasquerault, J. C. Gomet, and B. R. Rowe, Chem. Phys. Lett. 245, 407 (1995).

${ }^{2}$ A. Canosa, D. C. Parent, D. Pasquerault, J. C. Gomet, S. Laubé, and B. R. Rowe, Chem. Phys. Lett. 228, 26 (1994).

${ }^{3}$ S. Laubé, A. Le Padellec, O. Sidko, C. Rebrion-Rowe, J. B. A. Mitchell, and B. R. Rowe, J. Phys. B 31, 2111 (1998).

${ }^{4}$ I. Kato, T. Sakamoto, and T. Shimoda, Jpn. J. Appl. Phys., Part 1 33, 307 (1994).

${ }^{5}$ I. Kato, T. Sakamoto, and T. Yamagishi, Jpn. J. Appl. Phys., Part 1 33, 3586 (1994)

${ }^{6}$ E. V. Shun'ko, Rev. Sci. Instrum. 63, 2330 (1992).

${ }^{7}$ W. E. Amatucci, M. E. Koepke, T. E. Sheridan, M. J. Alport, and J. J. Carroll, Rev. Sci. Instrum. 64, 1253 (1993).

${ }^{8}$ D. Strele, M. Koepke, R. Schrittwieser, and P. Winkler, Rev. Sci. Instrum. 68, 3751 (1997).

${ }^{9}$ E. Alge, N. G. Adams, and D. Smith, J. Phys. B 16, 1433 (1983).

${ }^{10}$ B. R. Rowe, J. C. Gomet, A. Canosa, C. Rebrion, and J. B. A. Mitchell, J. Chem. Phys. 96, 1105 (1992).

${ }^{11}$ D. Smith and P. Spanel, in Experimental Methods in the Physical Sciences (Academic, Orlando, 1995), Vol. 29A, p. 273. 